\title{
AN EXPERIMENTAL STUDY ON THE SHEAR STRENGTH OF SFRC BEAMS WITHOUT STIRRUPS
}

\author{
Guray Arslan, Riza Secer Orkun Keskin, Semih Ulusoy \\ Yildiz Technical University, Department of Civil Engineering, Istanbul, Turkey \\ e-mail: aguray@yildiz.edu.tr; okeskin@yildiz.edu.tr; smhulusoy@gmail.com
}

\begin{abstract}
The use of steel fibers in reinforced concrete (RC) structural members aims at the improvement of mechanical properties of such members. This study focuses on shear strength characteristics of steel fiber reinforced concrete (SFRC) beams without stirrups. Test specimens consisting of three RC and ten SFRC beams without stirrups have been tested under three-point loading in order to investigate the effects of fiber content and shear span-to-effective depth ratio on the shear strength. Furthermore, an equation developed previously for predicting the ultimate shear strength of SFRC beams without stirrups is proposed to predict the diagonal cracking strength of SFRC beams without stirrups.
\end{abstract}

Keywords: steel fiber, reinforced concrete, shear strength, beam

\section{Introduction}

Concrete is a brittle material that has a relatively low tensile strength. This makes reinforced concrete (RC) beams without any shear reinforcement vulnerable to shear failure. Such brittle materials have been reinforced by using various types of fibers since ancient times. A substantial amount of research has been carried out to investigate the use of steel fibers for enhancing mechanical properties of concrete over the last half century (ACI, 1996). The focus of this study is on shear strength characteristics of low- and normal-strength steel fiber reinforced concrete (SFRC) beams without stirrups. It has been shown through experimental studies that the use of steel fibers improves those characteristics significantly (Batson et al., 1972; Kadir and Saeed, 1986; Mansur et al., 1986; Uomoto et al., 1986; Lim et al., 1987; Narayanan and Darwish, 1987; Li et al., 1992; Swamy et al., 1993; Noghabai, 2000; Kwak et al., 2002; Rosenbusch and Teutsch, 2002; Dupont and Vandewalle, 2003; Cucchiara et al., 2004; Parra-Montesinos, 2006; Parra-Montesinos et al., 2006; Dinh et al., 2010; Ding et al., 2011; Aoude et al., 2012; Minelli and Plizzari, 2013; Minelli et al., 2014; Sahoo and Sharma, 2014; Shoaib et al., 2014; Singh and Jain, 2014; Sahoo et al., 2015). Besides, various studies have been conducted to develop an accurate model for predicting the shear strength of SFRC beams without stirrups (Sharma, 1986; Narayanan and Darwish, 1987; Ashour et al., 1992, Swamy et al., 1993; Imam et al., 1997, Khuntia et al. 1999; Kwak et al., 2002; RILEM, 2003; Yakoub, 2011; Gandomi et al., 2011; Dinh et al., 2011; Arslan, 2014). Despite these studies, SFRC has not yet achieved a widespread structural use. It is essential to increase the experimental database for both verifying the current models and developing more accurate ones.

The objective of this study is to investigate shear strength characteristics of low- and normal-strength SFRC beams without stirrups experimentally. A total of thirteen specimens, three of which being RC and the others SFRC beams, have been tested under three-point loading in order to examine the effects of volume fraction of steel fibers $V_{f}$ and shear span-to-effective depth ratio $a / d$ on the shear strength of SFRC beams without stirrups. Furthermore, the ultimate shear strengths and diagonal cracking strengths of test specimens have been predicted by using 
a number of equations available in the literature, and a comparison of those predictions is presented. A modified version of the equation proposed by Arslan (2014) for predicting the ultimate shear strength of SFRC beams without stirrups is suggested for predicting the diagonal cracking strength of SFRC beams without stirrups.

\section{Experimental program}

Test specimens consisting of three RC and ten SFRC beams have been divided into three groups as A2.5, A3.5 and A4.5 series based on the shear span-to-effective depth ratio. The beams of A2.5 series have a shear span-to-effective depth ratio of 2.5 , which is usually defined as the lower limit for slender RC beams without stirrups. The shear span-to-effective depth ratios of the beams of A3.5 and A4.5 series have been chosen as 3.5 and 4.5, respectively, in order to observe shear failure resulting from diagonal tension. The geometrical properties of test specimens are shown in Fig. 1. All beams have the same cross-section of $150 \mathrm{~mm}$ by $230 \mathrm{~mm}$ with an effective depth of $200 \mathrm{~mm}$. The beams of A2.5 series are $1400 \mathrm{~mm}$ long, whereas the beams of A3.5 and A4.5 series are $2200 \mathrm{~mm}$ long.

(a)
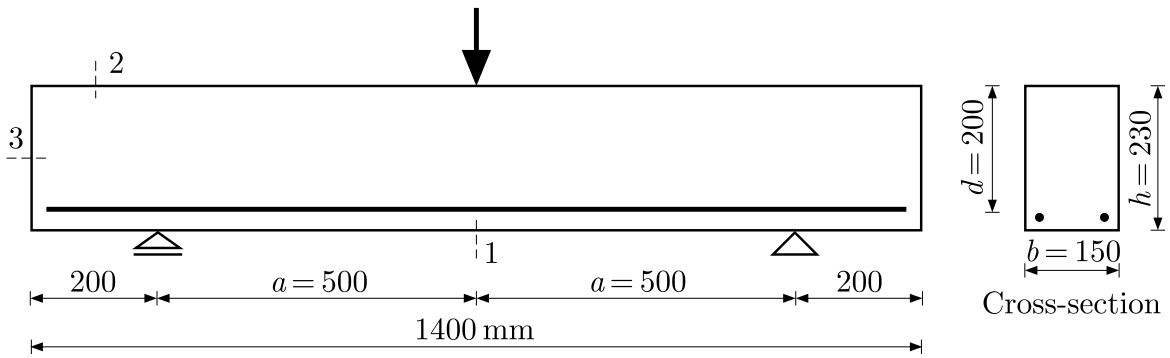

Cross-section

(b)

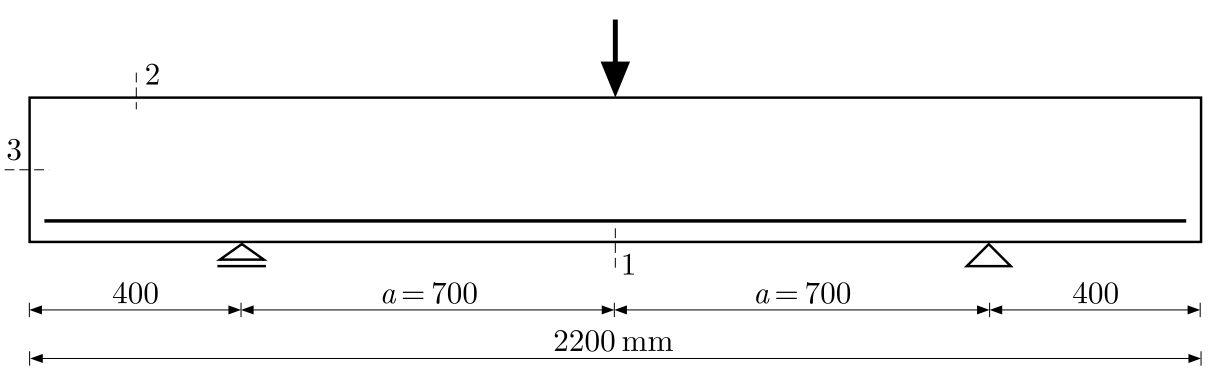

(c)

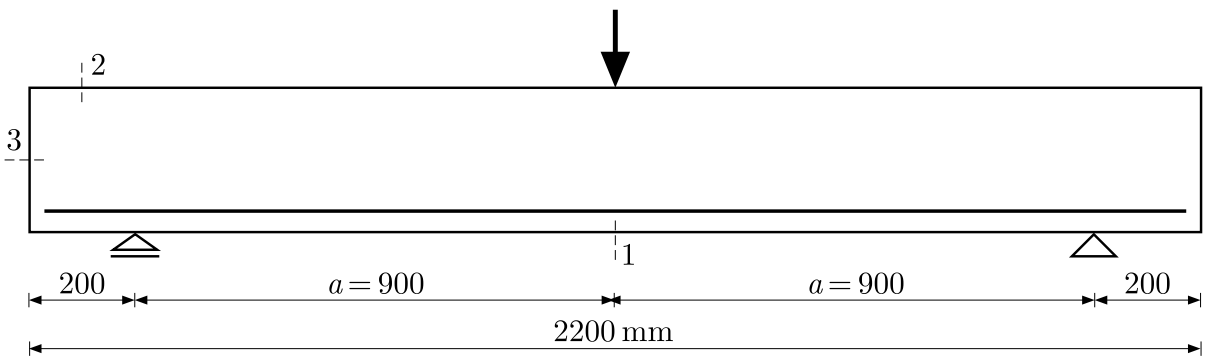

Fig. 1. Configuration and geometry of test specimens; (a) A2.5 series, (b) A3.5 series, (c) A4.5 series

A longitudinal reinforcement ratio $\rho$ of $1.34 \%$ has been chosen to avoid any premature flexural failure. Two deformed (S420 grade) steel bars of $16 \mathrm{~mm}$ diameter were used as the longitudinal reinforcement for all beams. Hooked-end steel fibers with a length $L_{f}$ of $30 \mathrm{~mm}$ and a nominal diameter $D_{f}$ of $0.55 \mathrm{~mm}$, resulting in an aspect ratio $L_{f} / D_{f}$ of 54.5 , were used as the only shear reinforcement. Each group of test specimens includes beams with the volume fraction of steel fibers ranging from $0.0 \%$ to $3.0 \%$. 
A specimen label consists of a combination of letters and numbers. Each label starts with an "A" followed by $2.5,3.5$ or 4.5 to designate the shear span-to-effective depth ratio and continues with an "F" to indicate the volume fraction of steel fibers followed by 1.0, 2.0 or 3.0 to designate the volume fraction of steel fibers. For example, a beam having a shear span-to-effective depth ratio of 3.5 with a volume fraction of steel fibers equal to $1.0 \%$ is labeled as A3.5F1.0. The specimens labeled as A2.5R, A3.5R and A4.5R are the reference beams that do not contain any steel fibers.

Table 1. Properties of test specimens

\begin{tabular}{|c|c|c|c|c|}
\hline Test specimen & $f_{c}[\mathrm{MPa}]$ & $V_{f}[\%]$ & $a / d$ & $l[\mathrm{~mm}]$ \\
\hline$\overline{\mathrm{A} 2.5 \mathrm{R}}$ & 39.00 & $\overline{0.0}$ & \multirow{5}{*}{2.5} & \multirow{5}{*}{1400} \\
\hline $\mathrm{A} 2.5 \mathrm{~F} 1.0 \mathrm{a}$ & 33.68 & 1.0 & & \\
\hline $\mathrm{A} 2.5 \mathrm{~F} 1.0 \mathrm{~b}$ & 24.53 & 1.0 & & \\
\hline $\mathrm{A} 2.5 \mathrm{~F} 2.0$ & 21.43 & 2.0 & & \\
\hline A2.5F3.0 & 9.77 & 3.0 & & \\
\hline A3.5R & 31.52 & 0.0 & \multirow{4}{*}{3.5} & \multirow{4}{*}{2200} \\
\hline A3.5F1.0 & 20.21 & 1.0 & & \\
\hline A3.5F 2.0 & 21.43 & 2.0 & & \\
\hline A3.5F3.0 & 27.91 & 3.0 & & \\
\hline $\mathrm{A} 4.5 \mathrm{R}$ & 41.82 & 0.0 & \multirow{4}{*}{4.5} & \multirow{4}{*}{2200} \\
\hline A4.5F 1.0 & 24.53 & 1.0 & & \\
\hline $\mathrm{A} 4.5 \mathrm{~F} 2.0$ & 21.43 & 2.0 & & \\
\hline A4.5F3.0 & 27.91 & 3.0 & & \\
\hline
\end{tabular}

The properties of test specimens are summarized in Table 1 , where $f_{c}$ is the concrete compressive cylinder strength and $l$ is the length of test specimen. All specimens have been cast with the concrete mix given in Table 2 . The concrete compressive strength of each specimen has been determined by using either $150 \times 150 \times 150 \mathrm{~mm}$ cube or $100 \times 100 \mathrm{~mm}$ cylinder samples. The concrete compressive strength of A2.5F3.0 is notably low compared to the others. This might have been occurred due to poor mixing and/or compacting of concrete leading to a relatively low concrete compressive strength.

Table 2. Concrete mix

\begin{tabular}{|c|c|c|}
\hline \multirow[t]{2}{*}{ Materials } & $\begin{array}{l}\mathrm{A} 2.5 \mathrm{R}, \mathrm{A} 2.5 \mathrm{~F} 3.0 \\
\mathrm{~A} 3.5 \mathrm{R}, \mathrm{A} 3.5 \mathrm{~F} 3.0 \\
\mathrm{~A} 4.5 \mathrm{R}, \mathrm{A} 4.5 \mathrm{~F} 3.0\end{array}$ & $\begin{array}{c}\mathrm{A} 2.5 \mathrm{~F} 1.0 \mathrm{a}, \mathrm{A} 2.5 \mathrm{~F} 1.0 \mathrm{~b} \\
\mathrm{~A} 2.5 \mathrm{~F} 2.0, \mathrm{~A} 3.5 \mathrm{~F} 1.0, \mathrm{~A} 3.5 \mathrm{~F} 2.0 \\
\mathrm{~A} 4.5 \mathrm{~F} 1.0, \mathrm{~A} 4.5 \mathrm{~F} 2.0\end{array}$ \\
\hline & \multicolumn{2}{|c|}{ Mixture proportions $\left[\mathrm{kg} / \mathrm{m}^{3}\right]$} \\
\hline 0-5 mm crushed sand & 1180 & 1150 \\
\hline 5-12 mm crushed stone & 721 & 310 \\
\hline 12-22 mm crushed stone & - & 470 \\
\hline Fly ash ( $40 \%$ of binder) & 80 & 90 \\
\hline Cement CEMI 42.5R & 240 & 220 \\
\hline Water/binder & 0.55 & 0.55 \\
\hline Superplasticizer & 3.20 & 3.10 \\
\hline
\end{tabular}

A load-controlled test procedure has been followed such that all specimens were incrementally loaded up to the failure. After each load increment, the deflections were measured by means of linear variable differential transducers (LVDTs) placed at locations 1, 2 and 3 shown in Fig. 1, and the crack pattern was monitored visually throughout the test. 


\section{Experimental results}

At the early stages of loading, fine vertical cracks were observed in the vicinity of mid-span of each beam. With the increasing load, new flexural cracks formed away the mid-span. With a further increase in the load, the flexural cracks started then to propagate diagonally towards the applied load and additional diagonal cracks began to form farther away the mid-span. The failure mechanisms of test specimens except for A4.5F2.0 and A4.5F3.0 were characterized by a wide diagonal crack. It was observed that (i) the failure mechanisms were controlled by an increased shear strength and the dowel effect, and reduced crack spacing and crack width resulting from the crack-bridging ability of steel fibers, and (ii) the specimens exhibited large deflections at failure. The crack patterns of test specimens at failure are shown in Fig. 2.

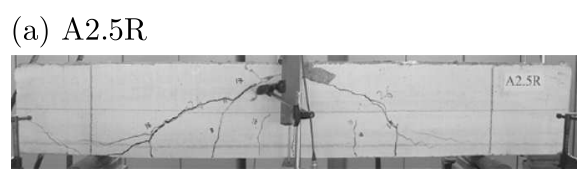

(c) A2.5F $1.0 \mathrm{~b}$

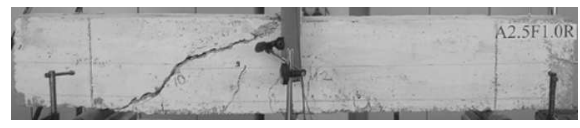

(e) A2.5F 3.0

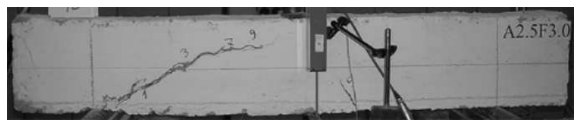

(g) A3.5F1.0

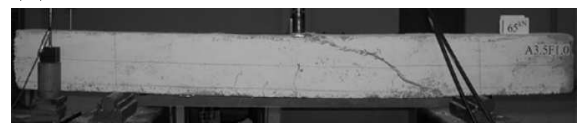

(i) A3.5F3.0

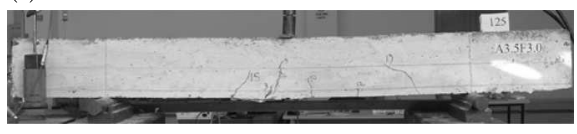

(k) A4.5F 1.0

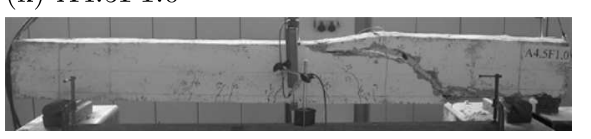

(b) A2.5F1.0a

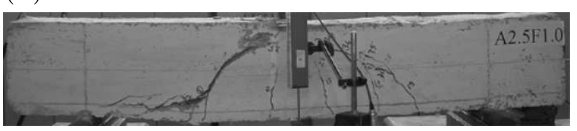

(d) A2.5F 2.0

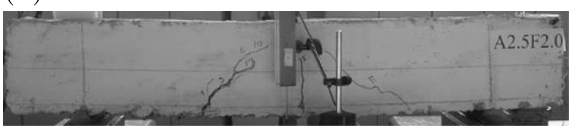

(f) A3.5R

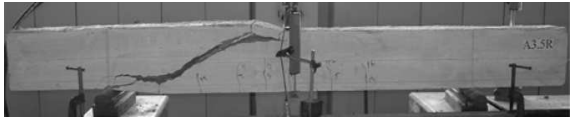

(h) A3.5F2.0

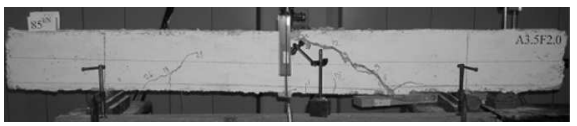

(j) A4.5R

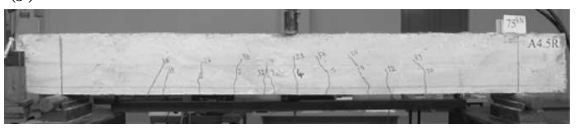

(l) $\mathrm{A} 2.5 \mathrm{~F} 2.0$

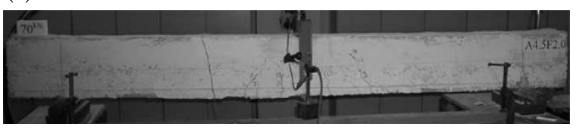

(m) A2.5F3.0

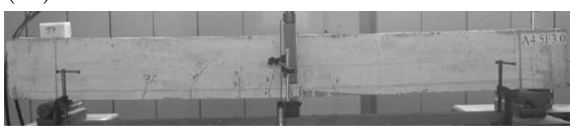

Fig. 2. Crack patterns of test specimens

It is usually assumed that the diagonal tension failure of an $\mathrm{RC}$ beam without stirrups initiates when the principal tensile stresses within the shear span exceed the tensile strength of concrete and a diagonal crack propagates through the beam web. In the studies of Arslan (2008, 2012) and Arslan and Polat (2013), a diagonal crack is defined as a major inclined crack extending from the level of the longitudinal reinforcement towards the applied load, and the load at the growth of the first inclined crack is termed as the diagonal cracking load. The diagonal cracking load $P_{c r}$, the mid-span deflection at diagonal cracking $\delta_{c r}$, the ultimate load $P_{u}$, the ultimate mid-span deflection $\delta_{u}$, the diagonal cracking strength $v_{c r}$ and the ultimate shear strength $v_{u}$ for each test specimen are given in Table 3, where the diagonal cracking strength and the ultimate 
shear strength are the diagonal cracking load and the ultimate load divided by the product of beam thickness $b_{w}$ and effective depth, respectively. The load-deflection curves of all specimens are plotted in Fig. 3.

Table 3. Experimental results

\begin{tabular}{|l|c|c|c|c|c|c|c|c|}
\hline $\begin{array}{c}\text { Test } \\
\text { specimen }\end{array}$ & $\begin{array}{c}P_{c r} \\
{[\mathrm{kN}]}\end{array}$ & $\begin{array}{c}\delta_{c r} \\
{[\mathrm{~mm}]}\end{array}$ & $\begin{array}{c}P_{u} \\
{[\mathrm{kN}]}\end{array}$ & $\begin{array}{c}\delta_{u} \\
{[\mathrm{~mm}]}\end{array}$ & $\begin{array}{c}v_{c r} \\
{[\mathrm{MPa}]}\end{array}$ & $\begin{array}{c}v_{u} \\
{[\mathrm{MPa}]}\end{array}$ & $\delta_{u} / \delta_{c r}$ & $v_{u} / v_{c r}$ \\
\hline \hline A2.5R & 65 & 1.23 & 81 & 1.89 & 1.08 & 1.35 & 1.54 & 1.25 \\
\hline A2.5F1.0a & 85 & 4.31 & 130 & 6.69 & 1.42 & 2.17 & 1.55 & 1.53 \\
\hline A2.5F1.0b & 70 & 4.41 & 88 & 5.71 & 1.17 & 1.47 & 1.29 & 1.26 \\
\hline A2.5F2.0 & 70 & 2.75 & 100 & 5.09 & 1.17 & 1.67 & 1.85 & 1.43 \\
\hline A2.5F3.0 & 60 & 4.90 & 78 & 7.79 & 1.00 & 1.30 & 1.59 & 1.30 \\
\hline A3.5R & 60 & 2.81 & 62 & 2.83 & 1.00 & 1.03 & 1.01 & 1.03 \\
\hline A3.5F1.0 & 55 & 2.80 & 65 & 4.26 & 0.92 & 1.08 & 1.52 & 1.17 \\
\hline A3.5F2.0 & 60 & 3.08 & 85 & 6.36 & 1.00 & 1.42 & 2.06 & 1.42 \\
\hline A3.5F3.0 & 95 & 5.09 & 117 & 6.83 & 1.58 & 1.95 & 1.34 & 1.23 \\
\hline A4.5R & 60 & 5.51 & 76 & 7.37 & 1.00 & 1.27 & 1.34 & 1.27 \\
\hline A4.5F1.0 & 60 & 4.60 & 85 & 8.70 & 1.00 & 1.42 & 1.89 & 1.42 \\
\hline A4.5F2.0* & 45 & 8.54 & 70 & 15.35 & 0.75 & 1.17 & 1.80 & 1.56 \\
\hline A4.5F3.0** & - & - & 97 & 18.63 & - & 1.62 & - & - \\
\hline
\end{tabular}

\subsection{Influence of volume fraction of steel fibers}

Experimental results given in Table 3 and Fig. 3 clearly show that the use of steel fibers improved the shear strength and deformation capacity considerably. In the case of A2.5 series, the use of steel fibers in the amounts of $1.0 \%$ and $2.0 \%$ by volume increased the ultimate shear strength by $9 \%$ and $23 \%$, respectively, and increased the deflection capacity 3.02 and 2.69 times, respectively. It is to be noted that increasing the volume fraction of steel fibers from $1.0 \%$ to $2.0 \%$ for approximately the same concrete compressive strength (A2.5F1.0b and A2.5F2.0) increased the ultimate shear strength by $14 \%$ but did not increase the deflection capacity. A2.5F3.0 cannot be compared directly since its concrete compressive strength is significantly low. In the case of A3.5 series, an increase in the ultimate shear strength due to the use of steel fibers in the amounts of $1.0 \%, 2.0 \%$ and $3.0 \%$ is $5 \%, 37 \%$ and $89 \%$, respectively, and the deflection capacity is increased 1.51, 2.25 and 2.41 times, respectively.

For a better understanding of the effect of fiber content on the shear strength, the normalized maximum shear stress against the volume fraction of steel fibers for each beam is plotted in Fig. 4 . It is clearly observed that the normalized maximum shear stress increases with the fiber content in the case of A2.5 and A3.5 series. A similar trend cannot be observed in the case of A4.5 series since A4.5F2.0 and A4.5F3.0 failed in flexure.

Even though the use of steel fibers enhanced the shear strengths and deformation capacities of the beams considerably, it was still not able to change the failure mechanisms of the beams of A2.5 and A3.5 series. On the other hand, the use of steel fibers in the amount of $3.0 \%$ in the case of A4.5 series both increased the shear strength and the deformation capacity by $28 \%$ and $152 \%$, respectively, and changed the failure mode from shear to flexure. It is to be noted that a high volume fraction of steel fibers, i.e. 3.0\%, was required to prevent the shear failure and use the flexural capacity. However, it may not be practical to work with a concrete mix having such a high volume fraction of steel fibers. Instead, steel fibers can be used together with a limited amount of stirrups to modify the failure mode. 

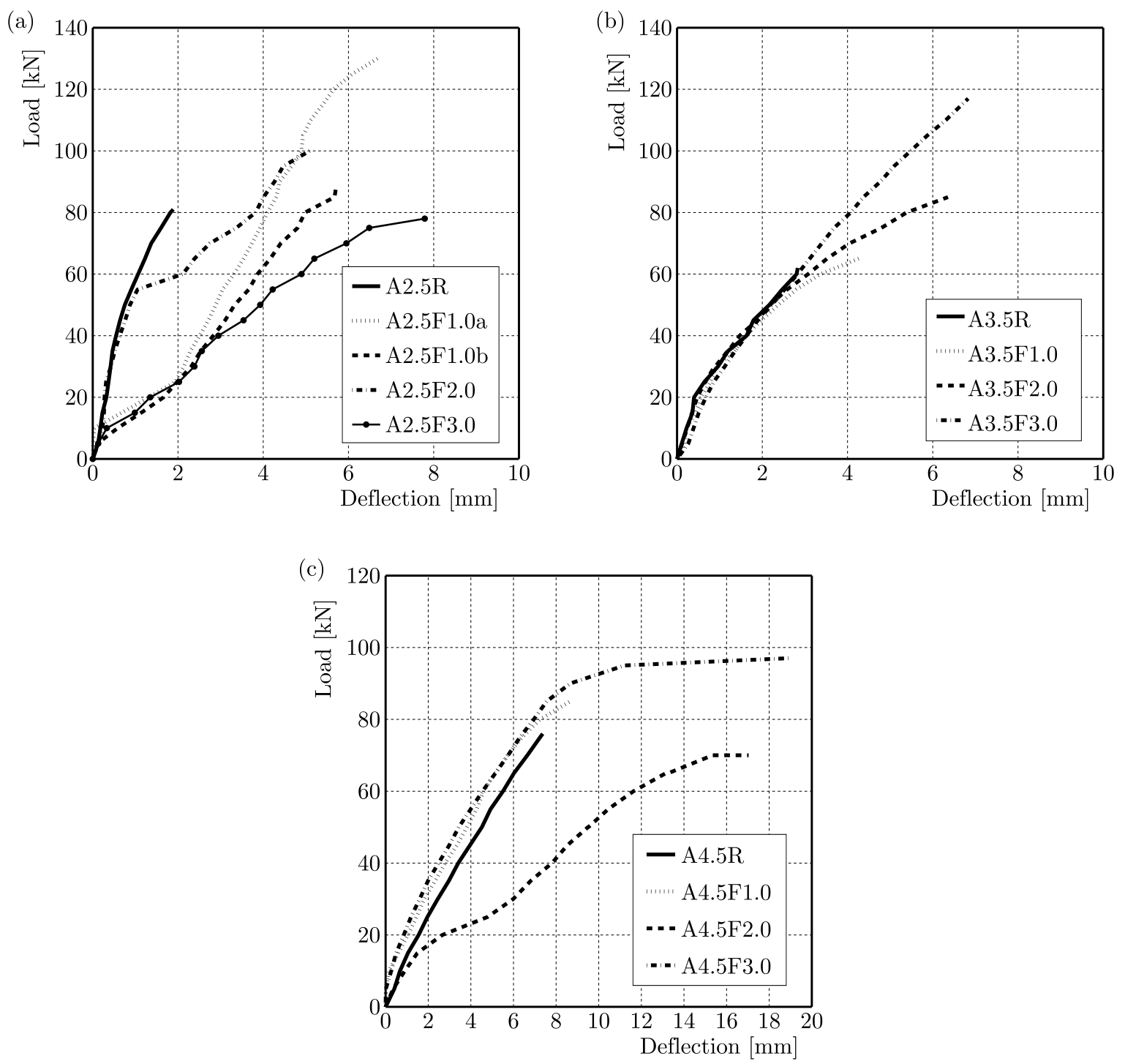

Fig. 3. Load-deflection curves; (a) A2.5 series, (b) A3.5 series, (c) A4.5 series

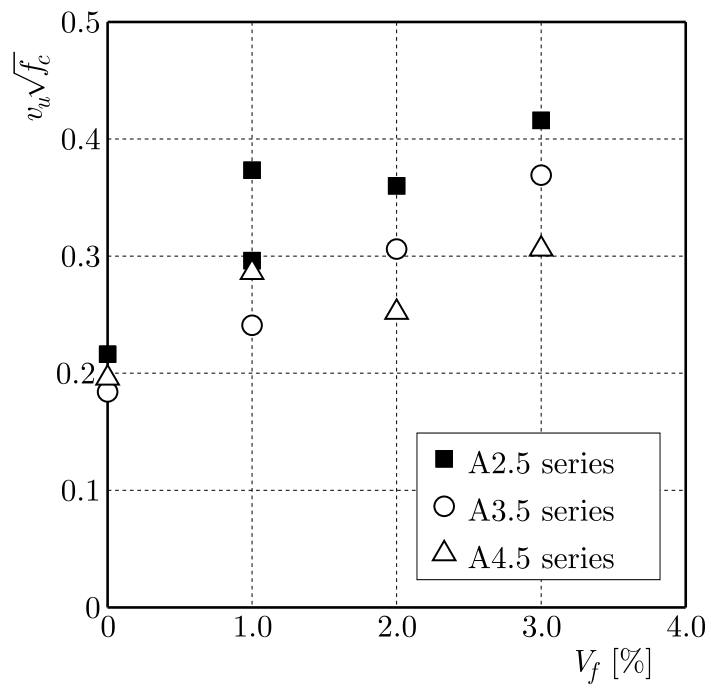

Fig. 4. Normalized maximum shear stress vs. fiber content 
It is observed in Table 3 that the ratio of the ultimate shear strength to the diagonal cracking strength increases with the volume fraction of steel fibers up to $2.0 \%$ for the beams of all three series, but decreases with an increase in the volume fraction of steel fibers from $2.0 \%$ to $3.0 \%$ for the beams of A2.5 and A3.5 series. A4.5F3.0 exhibited flexural failure and the diagonal cracking was not observed in this specimen.

\subsection{Influence of shear span-to-effective depth ratio}

It can be seen in Table 3 that the diagonal cracking strength decreases with the increasing shear span-to-effective depth ratio as a result of the increased flexural moment and the associated principal stresses and the diminishing arching effect. The shear span-to-effective depth ratio eventually affects the ultimate shear strength. As expected for the reference beams, the ultimate shear strength of A2.5R, which has the smallest shear span-to-effective depth ratio, is greater than that of the other reference beams; however it has a smaller deflection capacity. A similar relationship between the beams with the volume fraction of steel fibers of $2.0 \%$ is observed. A2.5F2.0 has a greater load carrying capacity and a smaller deflection capacity than A3.5F2.0 and A4.5F2.0 do.

It is observed that increase in the deflection capacity decreases with the increasing shear spanto-effective depth ratio for a given fiber content. The deflection capacities of A2.5F1.0b, A3.5F1.0 and A4.5F1.0 are 3.02, 1.51 and 1.18 times those of A2.5R, A3.5R and A4.5R, respectively. The use of steel fibers in the amount of $2.0 \%$ by volume resulted in deflection capacities 2.69, 2.25 and 2.08 times those of the reference specimens for A2.5F2.0, A3.5F2.0 and A4.5F2.0, respectively. Experimental results manifest that it is essential to consider the effect of shear span-to-effective depth ratio in predicting the shear strength of SFRC beams, as done by Sharma (1986), Narayanan and Darwish (1987), Ashour et al. (1992), Imam et al. (1997), Kwak et al. (2002), Gandomi et al. (2011) and Arslan (2014).

\section{Predicting the shear strengths of test specimens}

A number of equations proposed for predicting the ultimate shear strength and diagonal cracking strength of SFRC beams without stirrups are considered. The statistical evaluations of the equations considered within the scope of this study are available in the work of Arslan (2014). In this study, the equations are used only for predicting the ultimate shear strength and diagonal cracking strength of test specimens.

\subsection{The equations for ultimate shear strength}

Sharma (1986) proposed a simple empirical equation for predicting the ultimate shear strength of SFRC beams without stirrups. The equation, which is recommended by ACI (1988) $\left(v_{u}\right.$ in MPA), is

$$
v_{u}=k f_{c t}\left(\frac{d}{a}\right)^{0.25}
$$

where $f_{c t}$ is the concrete tensile strength, $k=1$ if $f_{c t}$ is obtained by a direct tension test, $k=2 / 3$ if $f_{c t}$ is obtained by an indirect tension test and $k=4 / 9$ if $f_{c t}$ is obtained by using the modulus of rupture or $f_{c t}=0.79 \sqrt{f_{c}}$.

Narayanan and Darwish (1987) proposed an empirical equation as

$$
v_{u}=e\left(0.24 f_{s p}+80 \rho \frac{d}{a}\right)+v_{b}
$$


where $e=1.0$ for $a / d>2.8$ and $e=2.8 d / a$ for $a / d \leqslant 2.8, f_{s p}=f_{\text {cuf }} /(20-\sqrt{F})+0.7+\sqrt{F}$ is the computed value of split-cylinder strength of fiber concrete, $f_{c u f}$ is the cube strength of fiber reinforced concrete, $F=\left(L_{f} / D_{f}\right) V_{f} d_{f}$ is the fiber factor $\left(d_{f}\right.$ is the fiber bond factor that is 0.5 for round, 0.75 for crimped and 1.0 for indented fibers), $v_{b}=0.41 \tau F$ is the pull-out strength of fibers along the inclined crack and $\tau$ is the average fiber matrix interfacial bond stress equal to 4.15 MPa.

Ashour et al. (1992) revised the equations given by the ACI 318 code (ACI, 2014) and Zsutty (1971) for predicting the ultimate shear strength of RC beams without stirrups in order to propose two empirical equations for SFRC beams with $a / d \geqslant 2.5$ as

$$
v_{u}=\left(0.7 \sqrt{f_{c}}+F\right) \frac{d}{a}+17.2 \rho \frac{d}{a} \quad v_{u}=\left(2.11 \sqrt[3]{f_{c}}+7 F\right) \sqrt[3]{\rho \frac{d}{a}}
$$

respectively.

Swamy et al. (1993) proposed an equation based on the truss model as

$$
v_{u}=0.37 \tau V_{f} \frac{L_{f}}{D_{f}}+0.167 \sqrt{f_{c}}
$$

where $\tau$ is assumed to be $4.15 \mathrm{MPa}$ as suggested by Narayanan and Darwish (1987).

Imam et al. (1997) modified the equation that Bazant and Sun (1987) had developed to predict the ultimate shear strength of $\mathrm{RC}$ beams without stirrups to propose the relationship

$$
v_{u}=0.6 \frac{1+\sqrt{5.08 / d_{a}}}{\sqrt{1+d / 25 d_{a}}} \sqrt[3]{\rho(1+4 F)}\left(f_{c}^{0.44}+275 \sqrt{\frac{\rho(1+4 F)}{(a / d)^{5}}}\right)
$$

where $d_{a}$ is the maximum aggregate size and $d_{f}$ is 0.5 for smooth, 0.9 for deformed and 1.0 for hooked fibers.

Khuntia et al. (1999) proposed the following equation

$$
v_{u}=(0.167+0.25 F) \sqrt{f_{c}}
$$

where $d_{f}$ is $2 / 3$ for plain and round, 1.0 for hooked or crimped fibers.

Kwak et al. (2002) developed an equation by using the form of the equation proposed by Zsutty (1971) combined with an additional term accounting for the contribution of steel fibers and proposed two versions of the equation with different constants as

$$
v_{u}=2.1 e f_{s p}^{0.7}\left(\rho \frac{d}{a}\right)^{0.22}+0.8 v_{b}^{0.97}
$$

where $e=1.0$ for $a / d>3.5$ and $e=3.5 d / a$ for $a / d \leqslant 3.5$, and

$$
v_{u}=3.7 e \sqrt[3]{f_{s p}^{2}} \sqrt[3]{\rho \frac{d}{a}}+0.8 v_{b}
$$

where $e=1.0$ for $a / d>3.4$ and $e=3.4 d / a$ for $a / d \leqslant 3.4$.

According to RILEM (2003), the ultimate shear strength of SFRC beams without stirrups is calculated as

$$
v_{R d, 3}=0.12 k \sqrt[3]{100 \rho f_{c}}+0.7 k_{f} k_{1} \tau_{f d}
$$

where $k=1+\sqrt{200 / d} \leqslant 2(d$ is in $\mathrm{mm}), \rho \leqslant 0.02, k_{f}$ is a factor considering the contribution of flanges in a T-section and is equal to 1 for rectangular sections, $k_{1}=1+\sqrt{200 / d} \leqslant 2(d$ is 
in $\mathrm{mm}), \tau_{f d}=0.12 f_{R k, 4}$ is the design value of increase in shear strength due to steel fibers and $f_{R k, 4}$ is the characteristic residual strength for the ultimate limit state.

Yakoub (2011) used an expression developed for predicting the contribution of steel fibers to the shear strength of SFRC beams to modify the equations given by Bazant and Kim (1984) and CSA A23.3-04 (CSA, 2004). The resulting equations for $a / d \geqslant 2.5$ are

$$
\begin{aligned}
& v_{u}=0.83 \xi \sqrt[3]{\rho}\left(\sqrt{f_{c}}+249.28 \sqrt{\frac{\rho}{(a / d)^{5}}}\right)+0.162 F \sqrt{f_{c}} \\
& v_{u}=\beta \sqrt{f_{c}}(1+0.70 F)
\end{aligned}
$$

respectively, where $\xi=1 / \sqrt{1+d /(25 d a)}$ is the aggregate size effect factor, $\beta=[0.4 /(1+$ $\left.\left.1500 \varepsilon_{x}\right)\right]\left[1300 /\left(1000+s_{x e}\right)\right]\left(s_{x e}\right.$ is in $\left.\mathrm{mm}\right), \varepsilon_{x}=\left(M / d_{v}+V\right) /\left(2 E_{s} A_{s}\right)$ is the longitudinal strain at the mid-depth of the beam web, $M$ and $V$ are the external failure moment and shear acting on the section, respectively, $d_{v}$ is the flexural lever arm equal to $0.9 d$ or $0.72 h$ ( $h$ is the beam height), whichever is greater, $s_{x e}=35 s_{x} /\left(16+d_{a}\right) \geqslant 0.85 s_{x}$ is the equivalent crack spacing factor that accounts for the maximum aggregate size effects on the shear strength, $s_{x}$ is the crack spacing parameter that accounts for the crack spacing at the mid-depth of the beam and $d_{f}$ is 0.79 for sheared, 0.83 for crimped, 0.89 for duoform, 0.91 for rounded, 0.92 for indented cut wire and 1.00 for hooked fibers.

Gandomi et al. (2011) developed a nonlinear model by means of linear genetic programming as

$$
v_{u}=2 \frac{d}{a}\left(\rho f_{c}+v_{b}\right)+2 \frac{d}{a} \frac{\rho}{(288 \rho-11)^{4}}+2
$$

Dinh et al. (2011) proposed an equation as the summation of the shear stress carried across the compression zone and the vertical component of the diagonal tension resistance provided by steel fibers, such that

$$
v_{u}=0.13 \rho f_{y}+1.2 \sqrt[4]{\frac{V_{f}}{0.0075}}\left(1-\frac{c}{d}\right)
$$

where $f_{y}$ is the yield strength of flexural reinforcement and $c$ is depth of the compression zone, which can be simply taken as $0.1 h$.

Arslan (2014) proposed an equation by considering the influences of the shear span-to-effective depth ratio, dowel strength of tensile reinforcement and contribution of steel fibers to the shear strength as

$$
v_{u}=\left(0.2 \sqrt[3]{f_{c}^{2}} \frac{c}{d}+\sqrt{\rho(1+4 F) f_{c}}\right) \sqrt[3]{\frac{3}{a / d}}
$$

where $(c / d)^{2}+\left(600 \rho / f_{c}\right)(c / d)-600 \rho / f_{c}=0$.

\subsection{The predictions for ultimate shear strength}

The ultimate shear strengths of test specimens excluding the reference beams (A2.5R, A3.5R and A4.5R), A4.5F2.0 and A4.5F3.0 - since they failed in shear-flexure and flexure, respectively - have been predicted by using Eqs. (4.1)-(4.13) and the predictions were compared with the experimental values. The mean value (MV), standard deviation (SD) and coefficient of variation $(\mathrm{COV})$ of the ratios of the experimental values to the corresponding predictions are given in Table 4. 
Table 4. Statistics of the ratios of the experimental values to the predictions

\begin{tabular}{|c|c|c|c|}
\hline The model & MV & $\mathrm{SD}$ & $\mathrm{COV}$ \\
\hline Sharma (1986) & $\overline{1.241}$ & $\overline{0.186}$ & 0.150 \\
\hline Narayanan and Darwish (1987) & 0.593 & 0.183 & 0.309 \\
\hline Ashour et al. (1992), Eq. (4.3) & 0.504 & 0.186 & 0.369 \\
\hline Ashour et al. (1992), Eq. $(4.3)_{2}$ & 0.783 & 0.214 & 0.274 \\
\hline Swamy et al. (1993) & 0.734 & 0.239 & 0.326 \\
\hline Imam et al. (1997) & 0.633 & 0.201 & 0.317 \\
\hline Khuntia et al. (1999) & 0.853 & 0.192 & 0.225 \\
\hline Kwak et al. (2002), Eq. (4.7) & 0.543 & 0.128 & 0.235 \\
\hline Kwak et al. (2002), Eq. (4.8) & 0.574 & 0.145 & 0.253 \\
\hline RILEM (2003) & 1.361 & 0.227 & 0.167 \\
\hline Yakoub (2011), Eq. $(4.10)_{1}$ & 0.858 & 0.126 & 0.147 \\
\hline Yakoub (2011), Eq. $(4.10)_{2}$ & 1.342 & 0.329 & 0.246 \\
\hline Gandomi et al. (2011) & 0.480 & 0.116 & 0.242 \\
\hline Dinh et al. (2011) & 0.725 & 0.172 & 0.238 \\
\hline Arslan (2014) & 0.833 & 0.098 & 0.118 \\
\hline
\end{tabular}

The equations proposed by Sharma (1986), RILEM (2003) and Yakoub (2011) (Eq. (4.10)2) underestimate the ultimate shear strengths of test specimens involved in this study, whereas the ones proposed by Narayanan and Darwish (1987), Ashour et al. (1992) (Eq. (4.3)1), Imam et al. (1997), Kwak et al. (2002) and Gandomi et al. (2011) largely overestimate the experimental values. It is observed from the statistics given in Table 4 that the equation proposed by Yakoub (2011) (Eq. (4.10) 2 ) and Arslan (2014) provide the most accurate predictions for the specimens involved in this study, where as the predictions of the equation of Arslan (2014) are slightly better. The ratios of the experimental values to the corresponding predictions of the equation of Arslan (2014) have a mean value of 0.833 with the lowest coefficient of variation equal to 0.118.

\subsection{The equations for diagonal cracking strength}

Narayanan and Darwish (1987) proposed an empirical equation for predicting the diagonal cracking strength as

$$
v_{c r}=0.24 f_{s p}+20 \rho \frac{d}{a}+0.5 F
$$

Kwak et al. (2002) proposed an equation by following a procedure similar to the one followed for developing Eqs. (4.7) and (4.8) as

$$
v_{c r}=3 \sqrt[3]{f_{s p}^{2}} \sqrt[3]{\rho \frac{d}{a}}
$$

The equation proposed by Arslan (2014) and given in Eq. (4.13) has been modified by introducing a strength reduction factor of 0.6 , which was obtained through a regression analysis undertaken to identify the strength reduction factor in calculating the diagonal cracking strength of SFRC slender beams without stirrups by using the results of existing experimental data. The resulting equation is

$$
v_{u}=0.6\left(0.2 \sqrt[3]{f_{c}^{2} 3} \frac{c}{d}+\sqrt{\rho(1+4 F) f_{c}}\right) \sqrt[3]{\frac{3}{a / d}}
$$




\subsection{The predictions for diagonal cracking strength}

The diagonal cracking strengths of test specimens containing steel fibers excluding A4.5F3.0 that failed in flexure have been predicted by using Eqs. (4.14)-(4.16). The mean value, standard deviation and coefficient of variation of the ratios of the experimental values to the corresponding predictions are given in Table 5. It is observed from Table 5 that Eq. (4.16) performed better in predicting the diagonal cracking strengths of the considered test specimens than the other equations do. The ratios of the experimental values to the corresponding predictions obtained from Eq. (4.16) have a mean value of 1.032 with the lowest coefficient of variation equal to 0.079.

Table 5. Statistics of the ratios of the experimental values to the predictions

\begin{tabular}{|l|c|c|c|}
\hline \multicolumn{1}{|c|}{ The model } & MV & SD & COV \\
\hline \hline Eq. (4.16) & 1.032 & 0.082 & 0.079 \\
\hline Narayanan and Darwish (1987) & 0.899 & 0.166 & 0.185 \\
\hline Kwak et al. (2002) & 1.102 & 0.131 & 0.119 \\
\hline
\end{tabular}

\section{Conclusion}

An experimental study has been conducted to investigate shear strength characteristics of lowand normal-strength SFRC slender beams without stirrups. The fact that the use of steel fibers improves the ultimate shear strength, diagonal cracking strength and ductility significantly is justified based on the following observations.

- The use of steel fibers with volume fractions of $1.0 \%$ and $2.0 \%$ increased the ultimate shear strength by $9 \%$ and $23 \%$, respectively, in the case of a shear span-to-effective depth ratio of 2.5 and by $5 \%$ and $37 \%$, respectively, in the case of a shear span-to-effective depth ratio of 3.5 .

- The use of steel fibers in an amount of 3.0\% was not able to change the failure mode of test specimens with a shear span-to-effective depth ratio of either 2.5 or 3.5, but it made the beam with a shear span-to-effective depth ratio of 4.5 fail in flexure instead of shear. However, it is to be noted that $3.0 \%$ may not be a practical volume fraction in the context of workability of a concrete mix. The use of steel fibers with a limited amount of stirrups can be a more practical way to modify the failure mode.

- The ratio of the ultimate shear strength to the diagonal cracking strength increased with the volume fraction of steel fibers up to $2.0 \%$ for all series of beams.

- The diagonal cracking strength decreased with the increasing shear span-to-effective depth ratio, which eventually affected the ultimate shear strength. This implies that it is essential to consider the effect of shear span-to-effective depth ratio in predicting the shear strength of SFRC beams.

- The use of steel fibers increased the deflection capacities significantly in all cases.

Besides the experimental study, the ultimate shear strengths and diagonal cracking strengths of SFRC beams involved in the experimental study were predicted by various equations available in the literature. Among the fifteen equations considered for predicting the ultimate shear strength of SFRC beams without stirrups, the equation proposed by Arslan (2014) had the best performance. The equation of Arslan (2014) was modified to predict the diagonal cracking strengths of SFRC beams involved in this study by introducing a strength reduction factor equal to 0.6. The modified equation had a better performance than those of the other two considered equations. Since the number of test specimens was limited, the modified version of the equation of Arslan (2014) should be verified with more data. 


\section{References}

1. ACI (American Concrete Institute), 1988, ACI 544.4R-88: Design Considerations for Steel Fiber Reinforced Concrete (Reapproved 1999), ACI, Farmington Hills, MI, USA

2. ACI, 1996, ACI 544.1R-96: State-of-the-Art Report on Fiber Reinforced Concrete (Reapproved 2009), ACI, Farmington Hills, MI, USA

3. ACI, 2014, ACI 318-14: Building Code Requirements for Structural Concrete and Commentary, ACI, Farmington Hills, MI, USA

4. Aoude H., Belghiti M., Cook W.D., Mitchell D., 2012, Response of steel fiber-reinforced concrete beams with and without stirrups, ACI Structural Journal, 109, 3, 359-367

5. Arslan G., 2008, Cracking shear strength of RC slender beams without web reinforcement, Journal of Civil Engineering and Management, 14, 3, 177-182

6. Arslan G., 2012, Diagonal tension failure of RC beams without stirrups, Journal of Civil Engineering and Management, 18, 2, 217-226

7. Arslan G., 2014, Shear strength of steel fiber reinforced concrete (SFRC) slender beams, KSCE Journal of Civil Engineering, 18, 2, 587-594

8. Arslan G., Polat Z., 2013, Contribution of concrete to shear strength of RC beams failing in shear, Journal of Civil Engineering and Management, 19, 3, 400-408

9. Ashour S.A., Hasanain G.S., WAFA F.F., 1992, Shear behavior of high-strength fiber reinforced concrete beams, ACI Structural Journal, 89, 2, 176-184

10. Batson G., Jenkins E., Spatney R., 1972, Steel fibers as shear reinforcement in beams, $A C I$ Journal Proceedings, 69, 10, 640-644

11. Bazant Z.P., Kim J.K., 1984, Size effect in shear failure of longitudinally reinforced beams, $A C I$ Journal Proceedings, 81, 5, 456-468

12. BazAnt Z.P., Sun H.H., 1987, Size effect in diagonal shear failure: influence of aggregate size and stirrups, ACI Materials Journal, 84, 4, 259-272

13. CSA (Canadian Standard Association), 2004, CSA A23.3-04: Design For Concrete Structures, Toronto, ON, Canada

14. Cucchiara C., La Mendola L., Papia M., 2004, Effectiveness of stirrups and steel fibres as shear reinforcement, Cement and Concrete Composites, 26, 7, 777-786

15. Ding Y., You Z., Jalali S., 2011, The composite effect of steel fibres and stirrups on the shear behaviour of beams using self-consolidating concrete, Engineering Structures, 33, 1, 107-117

16. Dinh H.H., Parra-Montesinos G.J., Wight J.K., 2010, Shear behavior of steel fiber-reinforced concrete beams without stirrup reinforcement, ACI Structural Journal, 107, 5, 597-606

17. Dinh H.H., Parra-Montesinos G.J., Wight J.K., 2011, Shear strength model for steel fiber reinforced concrete beams without stirrup reinforcement, ASCE Journal of Structural Engineering, 137, 10, 1039-1051

18. Dupont D., Vandewalle L., 2003, Shear capacity of concrete beams containing longitudinal reinforcement and steel fibers, ACI Special Publication, 216, 6, 79-94

19. Gandomi A.H., Alavi A.H., Yun G.J., 2011, Nonlinear modeling of shear strength of SFRC beams using linear genetic programming, Structural Engineering and Mechanics, 38, 1, 1-25

20. Imam M., Vandewalle L., Mortelmans F., 1994, Shear capacity of steel fiber high-strength concrete beams, SP-149: Proceedings of the ACI International Conference on High Performance Concrete, Singapore

21. KAdir M.R.A., SAEed J.A., 1986, Shear strength of fiber reinforced concrete beams, Engineering and Technology Journal, The Scientific Journal of the University of Technology, 4, 3, 98-112 
22. Khuntia M., Stojadinovic B., Goel S.C., 1999, Shear strength of normal and high-strength fiber reinforced concrete beams without stirrups, ACI Structural Journal, 96, 2, 282-289

23. Kwak Y.K., Eberhard M.O., Kim W.S., Kim J., 2002, Shear strength of steel fiber-reinforced concrete beams without stirrups, ACI Structural Journal, 99, 4, 530-538

24. Li V.C., Ward R., Hamza A.M., 1992, Steel and synthetic fibers as shear reinforcement, $A C I$ Materials Journal, 89, 5, 499-508

25. Lim T.Y., Paramasivam P., Lee S.L., 1987, Shear and moment capacity of reinforced steelfiber-concrete beams, Magazine of Concrete Research, 39, 140, 148-160

26. Mansur M.A., Ong K.C.G., Paramasivam P., 1986, Shear strength of fibrous concrete beams without stirrups, ASCE Journal of Structural Engineering, 112, 9, 2066-2079

27. Minelli F., Plizzari G.A., 2013, On the effectiveness of steel fibers as shear reinforcement, $A C I$ Structural Journal, 110, 3, 379-390

28. Minelli F., Conforti A., Cuenca E., Plizzari G.A., 2014, Are steel fibres able to mitigate or eliminate size effect in shear?, Materials and Structures, 47, 3,459-473

29. Narayanan R., Darwish I.Y.S., 1987, Use of steel fibers as shear reinforcement, ACI Structural Journal, 84, 3, 216-227

30. Noghabai K., 2000, Beams of fibrous concrete in shear and bending: experiment and model, ASCE Journal of Structural Engineering, 126, 2, 243-251

31. Parra-Montesinos G.J., 2006, Shear strength of beams with deformed steel fibers, Concrete International, 28, 11, 57-66

32. Parra-Montesinos G.J., Wight J.K., Dinh H.H., Libbrecht A., Padilla C., 2006, Shear Strength of Fiber Reinforced Concrete Beams without Stirrups, Report No. UMCEE 06-04, University of Michigan, Ann Arbor, MI, USA

33. RILEM, 2003, RILEM TC 162-TDF: Test and design methods for steel fibre reinforced concrete, stress-strain design method: final recommendation, Materials and Structures, 36, 8, 560-567

34. Rosenbusch J., Teutsch M., 2002, Trial Beams in Shear, Brite/Euram Project 97-4163, Final Report, Sub Task 4.2., Technical University of Braunschweig, Germany

35. Sahoo D.R., Sharma A., 2014, Effect of steel fiber content on behavior of concrete beams with and without stirrups, ACI Structural Journal, 111, 5, 1157-1166

36. Sahoo D.R., Maran K., Kumar A., 2015, Effect of steel and synthetic fibers on shear strength of RC beams without shear stirrups, Construction and Building Materials, 83, 150-158

37. Sharma A.K., 1986, Shear strength of steel fiber reinforced concrete beams, ACI Journal Proceedings, 83, 4, 624-628

38. Shoaib A., Lubell A.S., Bindiganavile V.S., 2014, Size effect in shear for steel fiber-reinforced concrete members without stirrups, ACI Structural Journal, 111, 5, 1081-1090

39. Singh B., JAIN K., 2014, An appraisal of steel fibres as minimum shear reinforcement in concrete beams, ACI Structural Journal, 111, 5, 1191-1202

40. Swamy R.N., Jones R., Chiam A.T.P., 1993, Influence of steel fibers on the shear resistance of lightweight concrete I-beams, ACI Structural Journal, 90, 1, 103-114

41. Uomoto T., Weerarathe R.K., Furukoshi H., Fujino H., 1986, Shear strength of reinforced concrete beams with fiber reinforcement, Proceedings: Third International RILEM Symposium on Developments in Fiber Reinforced Cement and Concrete, Sheffield, England, July, 313-325.

42. YAKOUB H.E., 2011, Shear stress prediction: steel fiber-reinforced concrete beams without stirrups, ACI Structural Journal, 108, 3, 304-314

43. Zsutty T., 1971, Shear strength prediction for separate categories of simple beam tests, $A C I$ Journal Proceedings, 68, 2, 138-143 